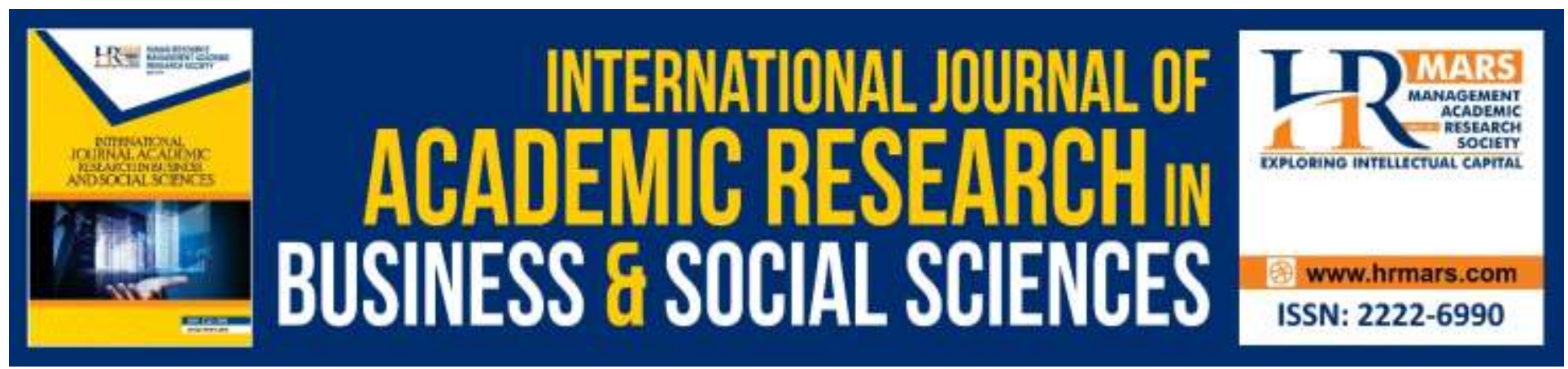

\title{
Review of Hybrid TOPSIS with other Methods
}

\author{
Abdulhadi Qays Abdulhadi
}

To Link this Article: http://dx.doi.org/10.6007/IJARBSS/v9-i14/6504

DOI:10.6007/IJARBSS/v9-i14/6504

Received: 22 August 2019, Revised: 13 September 2019, Accepted: 04 October 2019

Published Online: 20 October 2019

In-Text Citation: (Abdulhadi, 2019)

To Cite this Article: Abdulhadi, A. Q. (2019). Review of Hybrid TOPSIS with other Methods. International Journal of Academic Research in Business and Social Sciences, 9(14), 52-62.

\section{Copyright: (c) 2019 The Author(s)}

Published by Human Resource Management Academic Research Society (www.hrmars.com)

This article is published under the Creative Commons Attribution (CC BY 4.0) license. Anyone may reproduce, distribute, translate and create derivative works of this article (for both commercial and non-commercial purposes), subject to full attribution to the original publication and authors. The full terms of this license may be seen at: http://creativecommons.org/licences/by/4.0/legalcode

\section{Vol. 9, No. 14, Special Issue: Education 4.0: Future Learning, Pg. 52 - 62}

Full Terms \& Conditions of access and use can be found at

http://hrmars.com/index.php/pages/detail/publication-ethics 


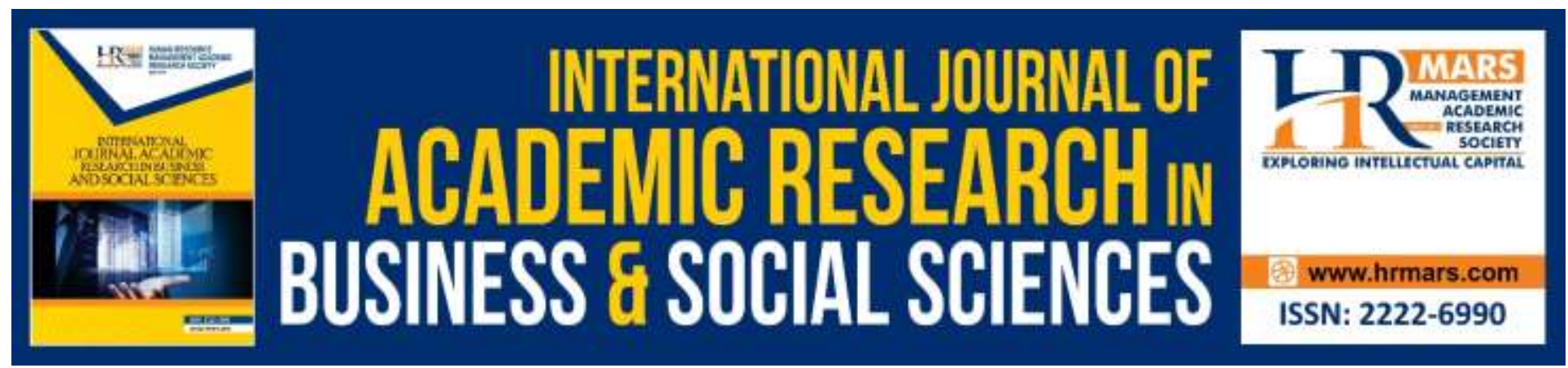

\title{
Review of Hybrid TOPSIS with other Methods
}

\author{
Abdulhadi Qays Abdulhadi \\ Faculty Art and Scietific Computing/ University Pendidikan Sultan Idris \\ Email: Phdhadi2016@gmail.com
}

\begin{abstract}
The Technique for Order Performance by Similarity to Ideal Solution (TOPSIS) has applied in many environments to solve the multi-criteria decision-making problem. In this paper, we have been categorized the articles that have been utilized TOPSIS and hybrid with others methods for solving decision-making problem. For that reason, the aim of this paper is to focus on the hybrid TOPSIS method to recognize the methods that have to apply with TOPSIS to enhancing the decision making from the final rank. TOPSIS have suffered from some weakness corresponding to weight election and distance measurement. The weight influence on the final decision making so that need more attention and the researches have assigned many techniques to solve this problem. Moreover, the distance measurement and influence on the final rank because the Euclidean distance could not reflect relative imported between the alternatives to the positive and negative ideal solution.
\end{abstract}

Keywords: MCDM, Topsis, Ahp, Saw, Entropy Method.

\section{Introduction}

Multiple criteria decision-making (MCDM) problems have appeared in many environments like supply chain management, risk assessment, network, Human Resource Competitiveness Energy, Industries, and etc. Moreover, all the environment need to involve human preferences to make the decision to solve these problems. Additionally, the MCDM problems can be divided into two level managerial and engineering (Ju \& Wang, 2012; Zhang, Liu, \& Guan, 2007). The managerial level is considering as describes the goals, specify the criteria for the goal, and can choose the ideal or optimal alternative. The multi-criteria environment of judgments is highlighted at this managerial level, and who make the judgment is called the decision maker (DM) (Du \& Yu, 2008; Guo-feng \& Li-wen, 2010). The decision maker can accept the optimal chose or discard it at this level. Moreover, the Decision maker has the power to accept or reject the solution proposed, also decision maker give his preference for the alternative through the procedure at the engineering level. An MCDM problem can be briefly expressed as a complex and dynamic method counting the decision makers level and mathematical level. The mathematical level presently, several MCDM methods produced and developed to explain and give a solution for a variety of this problems (Albahri, Zaidan, Albahri, Zaidan, \& Alsalem, 2018; Albahri et al., 2018; Kalid et al., 2018; Zaidan \& Zaidan, 2017a). 
Furthermore, there are many methods utilizing in MCDM for example, the analytical hierarchy process (AHP), AHP depends on the decisions of decision makers to decompose a difficult problematic into a hierarchy through the aim by the highest level of the hierarchy. The criteria of the sub -level of the hierarchy, and choose alternatives at the bottom level of the hierarchy (Işıklar \& Buyukozkan, 2007). Analytical network process (ANP) for DMs through dependency and response (Shyur, 2006). Simple Additive Weighting (SAW) the whole of an alternative is corresponding to the weight totality of its assessment evaluations (Sun, Miao, \& Yang, 2017). Techniques for order preference by similarity to an ideal solution (TOPSIS) is established on the idea which the greatest decision must remain the nearby the best solution and furthest from the worst solution (Yas, Zaidan, Zaidan, Rahmatullah, \& Karim, 2017; B. Zaidan \& Zaidan, 2017b; Zaidan, Karim, \& Ahmad, 2017). Grey relation analysis (GRA) is appropriate for resolving complications with complex interrelationships among several elements and variables. The Based on the grey system theory, the core process is to compute the grey relational score among the position arrangement and each additional comparison categorization (Wang, Zhu, \& Wang, 2016). The compromise ranking method (VIKOR) method presents a multi-criteria classification alternative based on the specific degree of nearness to the ideal solution (İç, 2012).

The conception of an ideal solution in TOPSIS method has established and acknowledged progressive comments from the researchers who worked on multi criteria decision making methods (Abdullateef, Elias, Mohamed, Zaidan, \& Zaidan, 2016; Qader et al., 2017; Yas, Zadain, Zaidan, Lakulu, \& Rahmatullah, 2017). The consequence to that, this article focus on TOPSIS method and reviewed the articles that conceder TOPSIS as main method to solving multi criteria decision making problem in different environment.

Moreover, in this article, did not focus on the studies that have been used TOPSIS because TOPSIS suffered from some problem and the researchers have to try to solve it via hybrid TOPSIS with other methods. It comes as no wonder that the most research works on hybrid TOPSIS and aimed to solve the multi-criteria decision-making (MCDM) problem, it denotes making decisions in the existence of the various inconsistent attribute.

\section{Traditional Topsis}

TOPSIS is one of most decision-making methods utilized by researches in a different environment to solve MCDM problem. TOPSIS have been developed by (Huang Yoon 1981). The main procedure and consideration of TOPSIS are measured the distance that computing between each alternative with positive and negative ideal solution. The nearest criteria to the positive solution and furthest from the negative solution remain higher scoring. TOPSIS has a sequence of stages which representative to list available of alternatives: normalization decision matrix, weighting criteria, recognize positive ideal solution and negative ideal solution, distance measurement. TOPSIS technique has been processed the following steps:

Step 1: Normalization. Is the first step that considers uniform the criteria from dissimilar measures into the same measure criterion. The matrix represented by and normalizing matrix form to utilizing the normalized formal in equation (1) After normalized the first matrix anew matrix presented call $\mathrm{R}$ as shown below: (2) Step 2: the next step is signed the Weighted for each criterion by decision making. The weight has been predefined as, and the weight have been signed for each criterion. The weight reflects 
the preferences of the decision maker then multiplied by the matrix $\mathrm{R}$. the total weight should be must be equal to one.

The Matrix $\mathrm{V}$ is the Matrix that resulted from multiply matrix $\mathrm{R}$ with weights as shown in equation 3:

$$
\mathrm{V}==(3)
$$

Step 3: Describing the positive and negative ideal solutions. In this step, the positive ideal solution is presented by and the negative ideal solution is presented by are calculated as in the below:

A new set of value denoted as is generated initial the previous process is a Subcategory of, these values describe benefit criterion of the positive ideal solution, although the negative ideal for cost criterion describe for is the auxiliary set of.

Step 4: the Euclidean distance is utilized for measuring the separation measurement. A new set of value denoted as is generated from this process is a set of that measure the distance from the alternative to the ideal solution. This process is done by:

Correspondingly, additional new established of value denoted as is produced after this process is a set of that measure the distance from the alternative to the negative ideal is given by:

(7)

For each alternative two processes namely and are accomplished to measure the distance between each alternative the best and worst values.

Step 5: Closeness to the ideal solution calculation. In the process, the closeness of to the ideal solution is defined as:

Step 6: Ranking the alternative according to the closeness to the ideal solution. In this step, alternative can be ordered decently where the higher value the better performance.

\section{The Utilized Of Hybrid TOPSIS in the Academic Literature}

TOPSIS have been applied in many studies that related to multi-criteria decision making (MCDM) problem. The articles specified that researchers are worried about several challenges related to the TOPSIS problem. Also, the researcher described the challenges for implementation of TOPISS method, besides with indications to situations in which the researcher be able to find the original proposal and additional discussion on those challenges. The challenges are categorized into collections conferring to their scope.

Furthermore, the most article that have found is utilized TOPSIS with AHP. Moreover, the inconsistency in the decision making that had made by the decision maker and can change the final rank. Normally the decision maker has a subjective decision that depends on his knowledgeable and professionals to make the decision and maybe has inconsistency, in remain esteemed besides operative for decision-making. Also, the inconsistency is generated when the decision making have complex decision and large comparative between criterions this has lied to inconsistency.

For that reason they have utilized AHP to check the inconsistency in the decision of the decision maker and get the subjective weight then applied for TOPSIS to get the final rank. 
Despite the fact that, there are other articles have tried to dismiss the subjective in their work because of inconsistency in the decision made and concentrated on the objective. Moreover, the objective is generated from the original data then apply for TOPSIS for getting the best solution so that the Entropy method has used for obtain the objective.

While, there is article that has analyzed the normalization step and tried to applied different normalization and comparison between them. The normalized decision matrix has obtained from three normalization which has influence on the final rank.

The rest of the articles have utilized different method for solve different problem. Furthermore, all the articles that have hybrid TOPSIS with other methods to solve multi-criteria decisionmaking problem in different environment as shown in table 1. Moreover, the articles have divided depending on the environment like Human resources, supplier selection, Network, Supplier chain management and others. In addition to that, TOPSIS have a different problem that researcher has worried about it and each research has to solve some problem too and represented there consider to this problem and apply the hybrid method related to the environment of their research.

Table 1, application of Tops is and hybrid with other methods

\begin{tabular}{|c|c|c|}
\hline Application of TOPSIS & Hybrid TOPSIS & oposed by \\
\hline \multirow[t]{2}{*}{ Human resources } & & \\
\hline & $\begin{array}{l}\text { Entropy weight and grey } \\
\text { relating with TOPSIS method. }\end{array}$ & $\begin{array}{l}\text { (Zhang et al., } \\
\text { 2007) }\end{array}$ \\
\hline \multirow[t]{2}{*}{$\begin{array}{l}\text { Emergency } \\
\text { evaluation }\end{array}$} & & \\
\hline & $\begin{array}{l}\text { DS/AHP with TOPSIS. } \\
\text { 2012) }\end{array}$ & (Ju \& Wang, \\
\hline Risk assessment model & AHP and rough set with TOPSIS. & $\begin{array}{l}\text { (Guo-feng \& Li- } \\
\text { wen, 2010) }\end{array}$ \\
\hline $\begin{array}{l}\text { Manufacturer supplier selection } \\
\text { Yu, 2008) }\end{array}$ & \multicolumn{2}{|c|}{ Entropy weight With TOPSIS method } \\
\hline Evaluation and Benchmarking & \multicolumn{2}{|c|}{$\begin{array}{r}\text { Different Normalization with TOPSIS (B. Zaidan \& } \\
\text { Zaidan, 2017a) }\end{array}$} \\
\hline \multirow[t]{2}{*}{$\begin{array}{l}\text { Evaluated mobile phone alternatives. } \\
\text { Buyukozkan, }\end{array}$} & AHP and TOPSIS method. & (Işıklar \& \\
\hline & \multicolumn{2}{|r|}{ 2007) } \\
\hline Commercial-off-the-shelf (COTS) & ANP with TOPSIS & (Shyur, 2006) \\
\hline Strategic emerging industries & Entropy weighted with TOPSIS. & (Sun et al., 2017) \\
\hline $\begin{array}{l}\text { Experimental design } \\
\text { 2016) }\end{array}$ & SAW, TOPSIS and GRA methods & (Wang et al., \\
\hline Experimental design & DOE with TOPSIS & (İç, 2012) \\
\hline Network selection & AHP-TOPSIS method & $\begin{array}{l}\text { (Mohamed, } \\
\text { Leghris, } \\
\text { Abdellah, 2011) }\end{array}$ \\
\hline
\end{tabular}


INTERNATIONAL JOURNAL OF ACADEMIC RESEARCH IN BUSINESS AND SOCIAL SCIENCES

Vol. 9, No. 14, Special Issue: Education 4.0: Future Learning. 2019, E-ISSN: 2222-6990 @ 2019 HRMARS

ETL software selection

AHP-TOPSIS method

(Hanine, Boutkhoum, Tikniouine, \& Agouti, 2016)

Personnel selection in manufacturing systems. ANP with TOPSIS

(Dağdeviren, 2010) Assessment of the cost-

effectiveness of companies Entropy weight TOPSIS.

(Dai \& Wang, 2011) A new MCDM method in planning 2011) Safety design Gray correlation degree and TOPSIS. (Dai \& Wang, 2009)

Supplier chain management

Entropy method TOPSIS

(C.-y. Zhao,

Entropy weight TOPSIS.

(Abidin, Rusli, \& Shariff, 2016)

Transmission network

Gray correlation degree and TOPSIS. (Liguo \& Yanhong, 2008)

E-Product E-Service and E-Entertainment (ICEEE), TOPSIS.

(M. Zhao \& Qiu, 2010)

Entropy weight

$A B C$ inventory classification.

AHP and Variable Neighborhood

(Kaabi \&

Search (VNS) TOPSIS

Jabeur, 2015)

Wireless networks.

Entropy method and AHP TOPSIS.(Sheng-mei, Su, \& Ming- hai, 2010)

Seismic shelter for evacuation in cities. Entropy method and AHP TOPSIS.(Chu \& Su, 2012) Selection of potential 3PL services providers AHP with TOPSIS

(Qureshi, Kumar, \& Kumar, 2007)

Ranking of product AHP with modify TOPSIS (Gangurde \& Akarte, 2010) Credit evaluation of construction-agency Entropy method and AHP TOPSIS.(Yunna, Ping, \& Wenjun,

software selection problem

AHP-TOPSIS method

(A. Zaidan et al., 2015)

optimization of GPS receiver tracking channels

AHP-TOPSIS method

(Jumaah, Zadain, Zaidan,

Hamzah, \&

Bahbibi, 2018) 


\section{Discussion}

The researches have been trying to improve the TOPSIS method respective to the weakness in the method. The first weakness in TOPSIS is the Weight problem. Generally in the TOPSIS procedure, the decision maker have to express his preferences via weight. Furthermore, the DM have to assign weight to each criterion and this weight may be unprecise. Additionally, the value of the weight for each criterion multiply with criteria and if the weight is not accurate will affect the final rank. Consequently, the research's has been hybrid TOPSIS with other methods to calculated weight for the decision maker. Moreover, there is two type of the weight subjective and objective weight (Jumaah et al., 2018; A. Zaidan et al., 2018; A. Zaidan et al., 2015; B. Zaidan, Zaidan, Karim, \& Ahmad, 2017).

To solve this problem the researchers have hybrid TOPSIS with other methods to calculate the subjective or objective weight. There are some authors have been proposed to utilized some method for assign the subjective weight the AHP with TOPSIS (Gangurde \& Akarte, 2010; Hanine et al., 2016; Işıklar \& Buyukozkan, 2007; Mohamed et al., 2011), while others have been utilized ANP for assign the weight with TOPSIS (Dağdeviren, 2010; Shyur, 2006). Although, the researchers focus on objective weight because there procedure is not interested in the human decision [7]. The other researchers have been utilized Entropy method for measuring the objective weight with TOPSIS (Abidin et al., 2016; Dai \& Wang, 2011; Du \& Yu, 2008; C.-y. Zhao, 2009; M. Zhao \& Qiu, 2010).

While, there is article that analyzed the mathematical step and influence of apply different normalization on the original data. The comparative start via apply (Vector normalization, Linear normalization 1, Linear normalization 2) and the result shows that each normalization has obtain different result (B. Zaidan \& Zaidan, 2017a).

Furthermore, there some researchers proposed to mix between subjective and objective weight, the authors utilized TOPSIS with the Variable Neighborhood Search (VNS) for produced objective weights incessant in addition utilized AHP subjective weights are created with TOPSIS (Kaabi \& Jabeur, 2015). AHP and information Entropy weight method combination weighing with TOPSIS (Chu \& Su, 2012; Qureshi et al., 2007; Sheng-mei et al., 2010).

Other researchers not only concentrate just about the weight problem but also worries about distance measurement between the ideal solution and alternatives. The MCDM inspection characteristic the evaluations of the benefits and strengths of each criterion based on the Euclidean distance between discretely criteria and the positive ideal solution and negative ideal solution.

In addition, the author has utilizing Entropy Weight and Grey Relating with TOPSIS Method to calculate the weight and the relative approximation between the criteria the positive and negative ideal solution (Zhang et al., 2007). SAW to sign the subjective weight for TOPSIS and utilized GRA methods for relative closeness between ideal solution and alternatives (Wang et al., 2016)

while there is another author proposed to mix between subjective and objective weight to determine the comprehensive weight also improve TOPSIS by adopted Minkowski distance instead of using Euclidean distance (Yunna et al., 2011). In addition, there is another author proposed to utilized AHP with modify TOPSIS through the weighted Euclidean distances (Gangurde \& Akarte, 2010). 


\section{Conclusion}

TOPSIS method is very powerful method, the researches have been utilized to solving a problem that have related to the MCDM problem. Moreover, the researchers worried about the step of TOPSIS procedure and some of this concerned is about the Weight because the weight is very important and can change the final rank. Consequently, the research's has been tried to solve this problem by hybrid TOPSIS with other methods, for example, AHP, ANP, SAW, entropy method and some of the proposed method to calculated the weight. In addition to that, others have combined the subjective and objective weight to get the comprehensive weight as the researcher idea the weight will be more precise.

Moreover, different normalization has influence on the final rank and need more analyzed for apply each one for suitable environment.

While, the other researchers have concerned about the distance measurement between the alternatives and positive and negative ideal solution. The Euclidean distance cannot reveal the importance of the closeness of the alternative to the ideal solution. Correspondingly, the some of the researchers have been utilized Grey Relating for distance measurement but there is another distance measurement can applied for measuring the distance between alternative and ideal solution like Manhattan or Mahalanobis distance and other.

\section{References}

Abdullateef, B. N., Elias, N. F., Mohamed, H., Zaidan, A., \& Zaidan, B. (2016). An evaluation and selection problems of OSS-LMS packages. SpringerPlus, 5(1), 248.

Abidin, M. Z., Rusli, R., \& Shariff, A. M. (2016). Technique for Order Performance by Similarity to Ideal Solution (TOPSIS)-entropy Methodology for Inherent Safety Design Decision Making Tool. Procedia Engineering, 148, 1043-1050.

Albahri, A., Zaidan, A., Albahri, O., Zaidan, B., \& Alsalem, M. (2018). Real-Time Fault-Tolerant mHealth System: Comprehensive Review of Healthcare Services, Opens Issues, Challenges and Methodological Aspects. Journal of medical systems, 42(8), 137.

Albahri, O., Zaidan, A., Zaidan, B., Hashim, M., Albahri, A., \& Alsalem, M. (2018). Real-Time Remote Health-Monitoring Systems in a Medical Centre: A Review of the Provision of Healthcare Services-Based Body Sensor Information, Open Challenges and Methodological Aspects. Journal of medical systems, 42(9), 164.

Chu, J., \& Su, Y. (2012). The application of TOPSIS method in selecting fixed seismic shelter for evacuation in cities. Systems Engineering Procedia, 3, 391-397.

Dagdeviren, M. (2010). A hybrid multi-criteria decision-making model for personnel selection in manufacturing systems. Journal of Intelligent manufacturing, 21(4), 451460.

Dai, L., \& Wang, J. (2011). Evaluation of the profitability of power listed companies based on entropy improved TOPSIS method. Procedia Engineering, 15, 4728-4732.

Du, Z.-h., \& Yu, C.-h. (2008). Analysis of the manufacture supplier selection with the improved technique for order preference by similarity to ideal solution. Paper presented the Management Science and Engineering, 2008. ICMSE 2008. 15th Annual Conference Proceedings., International Conference on.

Gangurde, S., \& Akarte, M. (2010). Ranking of product alternatives based on customerdesigner preferences. Paper presented at the Industrial Engineering and Engineering Management (IEEM), 2010 IEEE International Conference on. 
Guo-feng, W., \& Li-wen, C. (2010). Construction project bidding risk assessment model based on rough set-TOPSIS. Paper presented at the Information Engineering (ICIE), 2010 WASE International Conference on.

Hanine, M., Boutkhoum, O., Tikniouine, A., \& Agouti, T. (2016). Application of an integrated multi-criteria decision making AHP-TOPSIS methodology for ETL software selection. SpringerPlus, 5(1), 1.

Ic, Y. T. (2012). An experimental design approach using TOPSIS method for the selection of computer-integrated manufacturing technologies. Robotics and ComputerIntegrated Manufacturing, 28(2), 245-256.

Işıklar, G., \& Buyukozkan, G. (2007). Using a multi-criteria decision making approach to evaluate mobile phone alternatives. Computer Standards \& Interfaces, 29(2), 265274.

Ju, Y., \& Wang, A. (2012). Emergency alternative evaluation under group decision makers: A method of incorporating DS/AHP with extended TOPSIS. Expert Systems with Applications, 39(1), 1315-1323.

Jumaah, F., Zadain, A., Zaidan, B., Hamzah, A., \& Bahbibi, R. (2018). Decision-making solution based multi-measurement design parameter for optimization of GPS receiver tracking channels in static and dynamic real-time positioning multipath environment. Measurement, 118, 83-95.

Kaabi, H., \& Jabeur, K. (2015). TOPSIS using a mixed subjective-objective criteria weights for $A B C$ inventory classification. Paper presented at the Intelligent Systems Design and Applications (ISDA), 2015 15th International Conference on.

Kalid, N., Zaidan, A., Zaidan, B., Salman, O. H., Hashim, M., Albahri, O., \& Albahri, A. (2018). Based on Real Time Remote Health Monitoring Systems: A New Approach for Prioritization "Large Scales Data" Patients with Chronic Heart Diseases Using Body Sensors and Communication Technology. Journal of medical systems, 42(4), 69.

Liguo, F., \& Yanhong, L. (2008). A new MCDM method in transmission network planning based on gray correlation degree and TOPSIS. Paper presented at the Control Conference, 2008. CCC 2008. 27th Chinese.

Mohamed, L., Leghris, C., \& Abdellah, A. (2011). A hybrid approach for network selection in heterogeneous multi-access environments. Paper presented at the New Technologies, Mobility and Security (NTMS), 2011 4th IFIP International Conference on.

Qader, M., Zaidan, B., Zaidan, A., Ali, S., Kamaluddin, M., \& Radzi, W. (2017). A methodology for football player's selection problem based on multi-measurements criteria analysis. Measurement, 111, 38-50.

Qureshi, M., Kumar, D., \& Kumar, P. (2007). Selection of potential 3PL services providers using TOPSIS with interval data. Paper presented at the Industrial Engineering and Engineering Management, 2007 IEEE International Conference on.

Sheng-mei, L., Su, P., \& Ming-hai, X. (2010). An improved TOPSIS vertical handoff algorithm for heterogeneous wireless networks. Paper presented at the Communication Technology (ICCT), 2010 12th IEEE International Conference on.

Shyur, H.-J. (2006). COTS evaluation using modified TOPSIS and ANP. Applied mathematics and computation, 177(1), 251-259. 
Sun, L. Y., Miao, C. I., \& Yang, L. (2017). Ecological-economic efficiency evaluation of green technology innovation in strategic emerging industries based on entropy weighted TOPSIS method. Ecological Indicators, 73, 554-558.

Wang, P., Zhu, Z., \& Wang, Y. (2016). A novel hybrid MCDM model combining the SAW, TOPSIS and GRA methods based on experimental design. Information Sciences, 345, 27-45.

Yas, Q. M., Zadain, A., Zaidan, B., Lakulu, M., \& Rahmatullah, B. (2017). Towards on develop a framework for the evaluation and benchmarking of skin detectors based on artificial intelligent models using multi-criteria decision-making techniques. International Journal of Pattern Recognition and Artificial Intelligence, 31(03), 1759002.

Yas, Q. M., Zaidan, A., Zaidan, B., Rahmatullah, B., \& Karim, H. A. (2017). Comprehensive insights into evaluation and benchmarking of real-time skin detectors: Review, open issues $\&$ challenges, and recommended solutions. Measurement.

Yunna, W., Ping, L., \& Wenjun, C. (2011). Credit evaluation of construction-agency based on entropy AHP multi-attributes improved TOPSIS decision model. Paper presented at the E- Business and E-Government (ICEE), 2011 International Conference on.

Zaidan, A., Zaidan, B., Albahri, O., Alsalem, M., Albahri, A., Yas, Q. M., \& Hashim, M. (2018). A review on smartphone skin cancer diagnosis apps in evaluation and benchmarking: coherent taxonomy, open issues and recommendation pathway solution. Health and Technology, 1-16.

Zaidan, A., Zaidan, B., Hussain, M., Haiqi, A., Kiah, M. M., \& Abdulnabi, M. (2015). Multicriteria analysis for OS-EMR software selection problem: A comparative study. Decision support systems, 78, 15-27.

Zaidan, B., \& Zaidan, A. (2017a). Comparative Study on the Evaluation and Benchmarking Information Hiding Approaches Based Multi-Measurement Analysis Using TOPSIS Method with Different Normalisation, Separation and Context Techniques. Measurement.

Zaidan, B., \& Zaidan, A. (2017b). Software and hardware FPGA-based digital watermarking and steganography approaches: Toward new methodology for evaluation and benchmarking using multi-criteria decision-making techniques. Journal of Circuits, Systems and Computers, 26(07), 1750116.

Zaidan, B., Zaidan, A., Abdul Karim, H., \& Ahmad, N. (2017). A new approach based on multidimensional evaluation and benchmarking for data hiding techniques. International Journal of Information Technology \& Decision Making, 1-42.

Zaidan, B., Zaidan, A., Karim, H. A., \& Ahmad, N. (2017). A new digital watermarking evaluation and benchmarking methodology using an external group of evaluators and multi-criteria analysis based on 'large-scale data'. Software: Practice and Experience, 47(10), 1365- 1392.

Zhang, Z., Liu, P., \& Guan, Z. (2007). The evaluation study of human resources based on entropy weight and grey relating TOPSIS method. Paper presented at the Wireless Communications, Networking and Mobile Computing, 2007. WiCom 2007. International Conference on.

Zhao, C. Y. (2009). The study on the performance evaluation of enterprises knowledge value chain management based on entropy weight TOPSIS. Paper presented at the 
INTERNATIONAL JOURNAL OF ACADEMIC RESEARCH IN BUSINESS AND SOCIAL SCIENCES

Vol. 9, No. 14, Special Issue: Education 4.0: Future Learning. 2019, E-ISSN: 2222-6990 @ 2019 HRMARS

Management Science and Engineering, 2009. ICMSE 2009. International Conference on.

Zhao, M., \& Qiu, W. (2010). Improved TOPSIS method based on relative entropy. Paper presented at the E-Product E-Service and E-Entertainment (ICEEE), 2010 International Conference on. 